\title{
Perioperative use of tirofiban hydrochloride (Aggrastat) does not increase surgical bleeding after emergency or urgent coronary artery bypass grafting
}

\author{
Federico Bizzarri, MD \\ Sabino Scolletta, MD \\ Enrico Tucci, MD \\ Mara Lucidi, MD \\ Giuseppe Davoli, MD \\ Thomas Toscano, MD \\ Eugenio Neri, MD \\ Luigi Muzzi, MD \\ Giacomo Frati, MD
}

From the Instituto di Chirurgia Toracica, Cardiovascolare e Tecnologie Biomediche, Università degli Studi de Siena, Siena, Italy.

Received for publication Feb 5, 2001; revisions requested March 22, 2001; revisions received May 9, 2001; accepted for publication June 8, 2001.

Address for reprints: Federico Bizzarri, MD, Instituto de Chirurgia Toracica e Cardiov, Universita degli Studi de Siena, Policlinico le Scotte, Viale M. Bracci, Siena 53100, Italy (E-mail: bizzarri@unisi.it).

J Thorac Cardiovasc Surg 2001;122:1181-5

Copyright (C) 2001 by The American Association for Thoracic Surgery

$0022-5223 / 2001 \$ 35.00+0 \quad \mathbf{1 2} / \mathbf{1} / \mathbf{1 1 7 8 3 8}$

doi: $10.1067 / \mathrm{mtc} .2001 .117838$
Background: The platelet glycoprotein IIb/IIIa inhibitor tirofiban hydrochloride improves outcome in patients with acute coronary syndrome. Nevertheless, a considerable number of patients require emergency or urgent coronary artery bypass grafting and may be at increased risk of postoperative bleeding after treatment with this molecule. The aim of this study is to evaluate the incidence of bleeding complications among patients undergoing bypass grafting after treatment with tirofiban.

Methods: We investigated the influence of the molecule on postoperative bleeding after cardiac surgery, comparing 2 groups of patients undergoing emergency or urgent coronary artery bypass grafting: group $A(n=20)$ received tirofiban, and group $B(n=68)$ received conventional therapy with intravenous heparin up until the operation. A total of 88 patients underwent coronary artery bypass surgery within 2 hours of ceasing the hemodynamic study. Clinical outcome, chest tube outputs, bleeding complications, transfusion requirements, platelet and hemoglobin counts, and clinical complications were examined.

Results: Bleeding differences were noted between the 2 groups at 8, 16, and 24 hours postoperatively. The incidence of blood, platelet, and fresh frozen plasma transfusions was higher in the control group. Postoperative thrombocytopenia was preserved in group A $\left(199.5 \pm 70.4\right.$ vs $\left.150.6 \pm 33.410^{3} / \mathrm{mL}, P<.01\right)$. No significant differences were noted between the 2 groups in the incidence of perioperative myocardial infarction, but significant differences were noted in enzyme levels, length of stay in the intensive care unit, and length of stay in the hospital. No deaths were observed. Hospital morbidity was increased in group B because of factors that were not apparently linked with tirofiban infusion.

Conclusions: Patients may safely undergo coronary artery bypass surgery after treatment with tirofiban hydrochloride. This molecule, administered in the immediate preoperative period, has no adverse clinical effects and does not seem to negatively influence the incidence of perioperative myocardial infarction. Although extracorporeal circulation can modify platelet numbers and function, our ongoing data could show significant reduction in the loss of platelets induced by cardiopulmonary bypass, minor postoperative bleeding, and a minor transfusion requirement in general. 


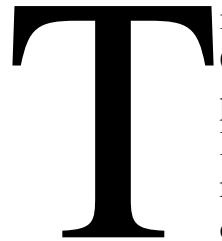
irofiban hydrochloride (Aggrastat; Merck \& $\mathrm{Co}$, Inc, West Point, Pa) is a reversible, nonpeptide inhibitor of the platelet glycoprotein $\mathrm{IIb} / \mathrm{III}$ a receptor, the major platelet surface receptor involved in platelet aggregation. In combination with heparin and aspirin, this molecule is indicated for the treatment of acute coronary syndrome because in this clinical setting, platelet-mediated coronary thrombosis is the primary pathophysiologic mechanism. Platelet aggregation leads to thrombotic occlusion of coronary arteries through cross-linking of glycoprotein IIb/IIIa receptors on adjacent platelets by means of adhesive plasma proteins, mostly fibrinogen.

Clinical studies (PRISM-PLUS, PRISM, and RESTORE) ${ }^{1,2}$ have confirmed the efficacy and safety of this kind of antithrombotic therapy in patients with acute coronary syndrome (irrespective of the presence of percutaneous transluminal coronary angioplasty). The impact of tirofiban and the other glycoprotein IIb/IIIa inhibitors (abciximab and eptifibatide) for the treatment of patients with acute coronary syndrome modified the clinical outcome of these patients, ${ }^{3}$ and therefore the horizon of the cardiac surgeon, because even if drug therapy is well tolerated, a significant number of patients need cardiac surgery after this treatment and may be at increased risk of bleeding complications, especially when emergency or urgent cardiac surgery is necessary. ${ }^{4,5}$ The role of tirofiban in patients with cardiac disease is not completely clear. It has been suggested that glycoprotein IIb/IIIa inhibitors with a short half-life, like tirofiban, have an improved safety profile and may produce platelet anesthesia during cardiopulmonary bypass (CPB) in experimental studies, ${ }^{6}$ preserving platelet numbers and function. The aim of this study was to assess the clinical events and potential bleeding complications in a cohort of patients who had undergone emergency or urgent cardiac surgery after treatment with tirofiban hydrochloride.

\section{Patients and Methods Patients}

From January 1999 to December 2000, a total of 764 coronary artery bypass grafting operations were done. From this group of patients, 88 underwent urgent or emergency treatment after acute coronary syndrome. Emergency treatment was carried out when the clinical status included shock, with or without circulatory support; pulmonary edema requiring intubation; acute evolving myocardial infarction within 24 hours before the operation; and ongoing ischemia, including angina at rest, despite maximal medical therapy. Urgent treatment was applied in cases of unstable angina with intravenous nitroglycerin or rest angina with or without an intra-aortic balloon pump and in cases of bad coronary anatomy, sudden chest pain, congestive heart failure, and acute myocardial infarction. Patients were classified into 1 of 2 groups: group A (tirofiban group, $\mathrm{n}=20$ ) received tirofiban treatment plus aspirin, and group $\mathrm{B}$ (control group, $\mathrm{n}=68$ ) received treatment with heparin plus aspirin. Group A comprised 14 male and 6 female patients and group B, 47 male and 21 female patients. Mean age was $60.9 \pm 8.7$ years in group $A$ and $63.2 \pm 9.1$ years in group B. Left main stem disease was equally present in both groups. Preoperative ejection fraction of the left ventricle was similar. Five (25\%) group A patients and 20 (29\%) group B patients required a significant dosage of a positive inotropic drug (defined as intravenous dopamine infusion over $\left.5 \mu \mathrm{g} \cdot \mathrm{kg}^{-1} \cdot \mathrm{min}^{-1}\right)$. Patients were classified according to the Higgins clinical severity score. ${ }^{7}$ Patient demographics, preoperative risk factors, and surgical times are summarized in Table 1.

Blood samples were obtained before and after the operation for the measurement of hemoglobin levels, platelet counts, prothrombin time, activated partial thromboplastin time, myocardial enzymes, and activated clotting time (ACT). Blood samples were taken before the operation (T1), after intensive care unit (ICU) admission (T2), and before hospital discharge (T3). Mediastinal chest tube output was collected in the ICU during the day of operation at the following time points: 8,16 , and 24 hours.

All group A patients with acute coronary syndrome (unstable angina or non-Q-wave myocardial infarction) underwent treatment with intravenous aspirin (bolus of $325 \mathrm{mg}$ ) and intravenous heparin (bolus of $5000 \mathrm{IU}$ followed by an infusion of $1000 \mathrm{IU} / \mathrm{h}$ titrated to maintain an activated partial thromboplastin time of approximately 2 times the control dose). Tirofiban was given as a bolus dose at a dosage of $0.4 \mu \mathrm{g} \cdot \mathrm{kg}^{-1} \cdot \mathrm{min}^{-1}$. Maintenance was achieved by giving $0.10 \mu \mathrm{g} \cdot \mathrm{kg}^{-1} \cdot \mathrm{min}^{-1}$. The infusion of tirofiban must be given for a maximum of 72 hours. Patients with renal failure (creatinine level $>2.0 \mathrm{mg} / \mathrm{dL}$ ) were appointed to receive a halfdose bolus and maintenance. Group B patients received only aspirin plus heparin, as above. Tirofiban and heparin discontinuation was only accomplished at skin incision.

\section{Operative Technique}

Patients were operated on through a median sternotomy. Extracorporeal circulation with a roller pump and a hollow-fiber oxygenator (Capiox SX18; Terumo Corporation, Tokyo, Japan) primed with $1800 \mathrm{~mL}( \pm 200 \mathrm{~mL})$ of buffered crystalloid solution was instituted. Heparin (300 IU/kg) was given before cannulation to achieve an ACT of greater than 400 seconds before CPB was carried out. During $\mathrm{CPB}$, the hematocrit level was maintained between $20 \%$ and $25 \%$. Myocardial protection was obtained according to the protocol of the University of California at Los Angeles Medical Center, ${ }^{8}$ with cold blood cardioplegic solution delivered antegradely and retrogradely from the coronary sinus. Before crossclamp release, modified cardioplegic reperfusion was performed. ${ }^{9}$ The patients were weaned off $\mathrm{CPB}$ when rectal temperature reached $34^{\circ} \mathrm{C}$. After discontinuation of $\mathrm{CPB}$, heparin was reversed with protamine sulfate by use of a heparin-ACT doseresponse curve. Patients were weaned off mechanical ventilation as soon as they were awake and breathing above the ventilator set rate and when the following criteria were met: patient awake and obeying commands; stable and adequate hemodynamics; no significant arrhythmia; core temperature of greater than $36^{\circ} \mathrm{C}$; chest tube drainage of less than $100 \mathrm{~mL} / \mathrm{h}$ for 2 consecutive hours; diuresis of greater than $1 \mathrm{~mL} \cdot \mathrm{kg}^{-1} \cdot \mathrm{h}^{-1} ; \mathrm{pH}$ of greater than 7.35; $\mathrm{PaCO}_{2}$ of less than $50 \mathrm{~mm} \mathrm{Hg} ; \mathrm{PaO}_{2}$ of greater than $70 \mathrm{~mm} \mathrm{Hg}$; and 
TABLE 1. Patient demographics, preoperative risk factors, and surgical time

\begin{tabular}{|c|c|c|c|}
\hline Value & $\begin{array}{l}\text { Tirofiban group } \\
\quad(\mathbf{n}=\mathbf{2 0})\end{array}$ & $\begin{array}{c}\text { Control group } \\
(n=68)\end{array}$ & $P$ value \\
\hline Age (y) & $60.9 \pm 8.7$ & $63.2 \pm 9.1$ & .31 \\
\hline Age $(\min / \max )$ & $45 / 74$ & $47 / 82$ & - \\
\hline Male sex $(\%)$ & 70 & 69 & .84 \\
\hline Weight (kg) & $77.8 \pm 17.2$ & $72.7 \pm 12.7$ & .23 \\
\hline $\operatorname{BSA}\left(\mathrm{m}^{2}\right)$ & $1.7 \pm 0.6$ & $1.8 \pm 0.2$ & .47 \\
\hline $\mathrm{EF}(\%)$ & $55.4 \pm 4.5$ & $56.8 \pm 5.1$ & .24 \\
\hline Left main stem (\%) & 50 & 51 & .89 \\
\hline ASA (\%) & 83 & 76 & .87 \\
\hline Higgins score & $6.9 \pm 1.4$ & $7.4 \pm 1.6$ & .18 \\
\hline Surgery time (min) & $230.8 \pm 51.4$ & $239.8 \pm 46.7$ & .48 \\
\hline Vessels bypassed ( $n$ ) & $1.3 \pm 0.8$ & $1.4 \pm 0.7$ & .63 \\
\hline ITA (n) & $1.2 \pm 0.7$ & $0.7 \pm 0.4$ & .01 \\
\hline CPB time (min) & $90.4 \pm 32.8$ & $104.2 \pm 31.5$ & .10 \\
\hline Aortic crossclamp time (min) & $68.2 \pm 27.9$ & $71.1 \pm 21.1$ & .67 \\
\hline
\end{tabular}

Values are expressed as means $\pm \mathrm{SD}$ where shown. $B S A$, Body surface area; $E F$, ejection fraction; $A S A$, acetylsalicilate acid; ITA, internal thoracic artery grafts.

oxygen saturation as measured by pulse oximetry of $92 \%$ or greater with the patient breathing less than $50 \%$ oxygen.

\section{Statistical Analysis}

Statistical analysis was performed with SPSS for Windows, version 8.0 software (SPSS Inc, Chicago, Ill). Analysis of variance for repeated measures and the Student $t$ test were applied to continuous variables. The $\chi^{2}$ test or, when appropriate, the Fisher exact test was applied to categoric variables. The Mann-Whitney rank sum test and Mann-Whitney $U$ test were also applied for categoric variables or when data did not follow a normal distribution. The data are presented as means $\pm \mathrm{SD}$.

\section{Results}

In the immediate postoperative time (T2), we observed a significant reduction in hemoglobin levels in both groups compared with that of the preoperative time (T1): group A, $13.1 \pm 0.9$ vs $11.1 \pm 1.2 \mathrm{~g} / \mathrm{dL}$ (T1 vs T2, $P<.01)$; group B, $13.5 \pm 0.8$ vs $10.3 \pm 1.1 \mathrm{~g} / \mathrm{dL}$ (T1 vs T2, $P<.01)$. Before hospital discharge (T3), hemoglobin values remained constant in both groups. There was a significant difference in hemoglobin levels between the tirofiban and control groups at T2 (group A: $11.1 \pm 1.2 \mathrm{~g} / \mathrm{dL}$ vs group B: $10.3 \pm 1.1 \mathrm{~g} / \mathrm{dL}$, $P<.01$ ) and T3 (group A: $10.9 \pm 1 \mathrm{~g} / \mathrm{dL}$ vs group B: $10.1 \pm$ $1.1 \mathrm{~g} / \mathrm{dL}, P<.01$; Figure 1$)$.

Platelet values were similar in both groups at T1 $(229 \pm$ 31.2 vs $227.8 \pm 29.710^{3} / \mathrm{mL}$, group A vs group $\mathrm{B}, P=.87$ ) but significantly different at T2 $(199.5 \pm 70.4$ vs $150.6 \pm$ $33.410^{3} / \mathrm{mL}$, group A vs group $\left.\mathrm{B}, P<.01\right)$. We did not observe a significant decrease in platelet numbers in the tirofiban group between $\mathrm{T} 1$ and $\mathrm{T} 2$, whereas a significant

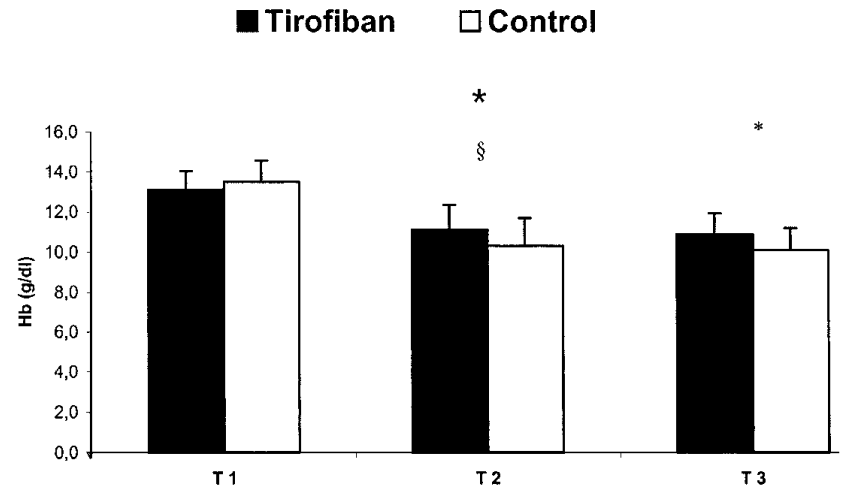

Figure 1. Changes in hemoglobin $(\mathrm{Hb})$ levels at different time points. Hemoglobin levels dropped significantly in both groups at T2. The difference in hemoglobin levels between the tirofiban and control groups is statistically significant at T2 and T3. ${ }^{*} P<.05$, tirofiban versus control. $\$ P<.001$, tirofiban and control (T1 vs T2).

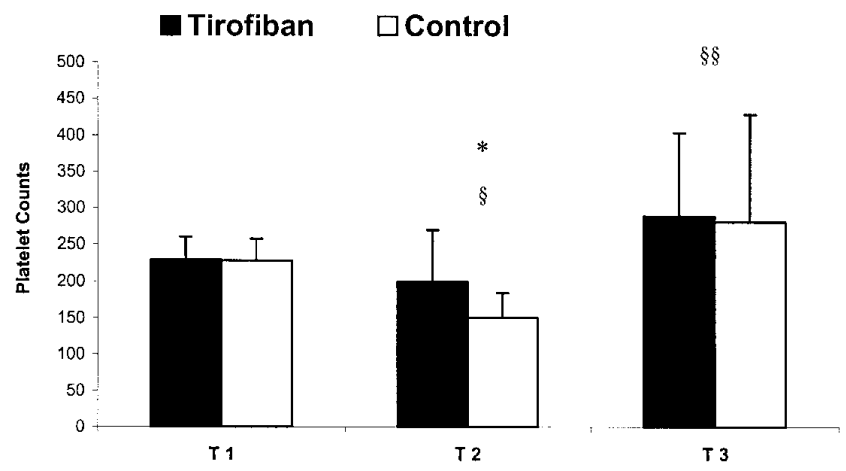

Figure 2. Change in platelet count. A significant reduction is seen between groups at $\mathrm{T} 2$. There is a significant reduction in platelet count in the control group between $\mathrm{T} 1$ and $\mathrm{T} 2$. At T3, an increase in the control group could be related to platelet transfusions. ${ }^{*} \boldsymbol{P}<$ .05 , tirofiban versus control. $\S P=.01$, control (T1 vs T2). $\S \S P<.05$, tirofiban and control (T2 vs T3).

reduction was seen between $\mathrm{T} 1$ and $\mathrm{T} 2$ in group $\mathrm{B}(227.8 \pm$ 27.9 vs $150.6 \pm 33.410^{3} / \mathrm{mL}$, T1 vs T2, $\left.P<.01\right)$.

At $\mathrm{T} 3$, the platelet count revealed comparable values between the 2 groups, and there was a significant increase in platelet number with respect to T2 $(199.5 \pm 70.4$ vs 288.8 $\pm 115.210^{3} / \mathrm{mL}$, group A, T2 vs T3, $P<.01 ; 150.6 \pm 33.4$ vs $281.3 \pm 147.610^{3} / \mathrm{mL}$, group $\mathrm{B}, \mathrm{T} 2$ vs T3, $P<.01$; Figure 2).

Two (10\%) patients in the tirofiban group and $28(41 \%)$ patients in the control group received a transfusion $(P=$ $.02)$. There was a significant difference between the number of units transfused in the control group, not only in red blood cells but also in plasma and platelets (Table 2). There was a significant difference in bleeding between the 2 


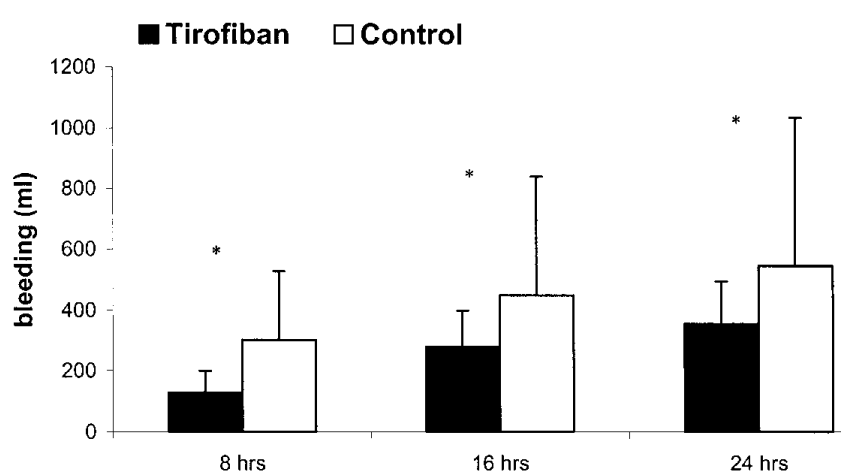

Figure 3. Chest tube drainage. Note the significant difference in postoperative bleeding between the 2 groups after 8, 16, and 24 hours. ${ }^{*} P<.01$.

TABLE 2. Laboratory parameters before and after surgical intervention, incidence of bleeding, chest tube output, transfusion requirements, and hospital and ICU length of stay

\begin{tabular}{|c|c|c|c|}
\hline & $\begin{array}{l}\text { Tirofiban group } \\
\quad(\mathrm{n}=20)\end{array}$ & $\begin{array}{c}\text { Control group } \\
(\mathrm{n}=68)\end{array}$ & $P$ value \\
\hline Preoperative ACT (s) & $107.2 \pm 16.3$ & $104.8 \pm 10.6$ & .54 \\
\hline Postoperative ACT (s) & $108.1 \pm 18.1$ & $106.7 \pm 11.2$ & .74 \\
\hline Preoperative PT (\%) & $86.3 \pm 8.1$ & $86.2 \pm 8.4$ & .96 \\
\hline Postoperative PT (\%) & $77.8 \pm 15.4$ & $78.2 \pm 11.7$ & .91 \\
\hline Preoperative APTT (s) & $72.4 \pm 29.4$ & $64.8 \pm 32.5$ & .32 \\
\hline Postoperative APTT (s) & $34.2 \pm 10.7$ & $36.8 \pm 10.6$ & .34 \\
\hline Preoperative total CK (IU/L) & $149.7 \pm 232$ & $134.5 \pm 53.2$ & .77 \\
\hline Preoperative MB (IU/L) & $6.17 \pm 5.4$ & $6.92 \pm 7.8$ & .60 \\
\hline Preoperative MB (\%) & $6.3 \pm 2.7$ & $5.9 \pm 2.6$ & .60 \\
\hline Postoperative total CK (IU/L) & $316.5 \pm 137$ & $490 \pm 297$ & .00 \\
\hline Postoperative MB (IU/L) & $25.3 \pm 20.3$ & $38.1 \pm 23.6$ & .03 \\
\hline Postoperative MB (\%) & $7.2 \pm 4.4$ & $9.6 \pm 3.1$ & .03 \\
\hline СТ0, $8 \mathrm{~h}(\mathrm{~mL})$ & $127.5 \pm 71.6$ & $300.3 \pm 226.3$ & .00 \\
\hline СТ0, $16 \mathrm{~h}(\mathrm{~mL})$ & $277.5 \pm 119.7$ & $448.2 \pm 390.5$ & .00 \\
\hline СТO, $24 \mathrm{~h}(\mathrm{~mL})$ & $354.5 \pm 139.6$ & $544.5 \pm 488.7$ & .00 \\
\hline Patients transfused (n) & $2(10 \%)$ & $28(41 \%)$ & .02 \\
\hline PRBC $(\mathrm{mL})$ & $50 \pm 116.8$ & $308.8 \pm 466.4$ & .00 \\
\hline FFP (units) & $0.3 \pm 0.8$ & $1.23 \pm 1.5$ & .00 \\
\hline PLT (units) & 0 & $0.98 \pm 1.1$ & .00 \\
\hline MV (h) & $11.5 \pm 4.6$ & $15.1 \pm 8.3^{*}$ & .01 \\
\hline ICU stay (h) & $27.4 \pm 12.8$ & $55.1 \pm 34.4$ & .00 \\
\hline Hospital stay (d) & $6.4 \pm 2.5$ & $13.9 \pm 3.7$ & .00 \\
\hline
\end{tabular}

Values are expressed as means \pm SD where shown. PT, Prothrombin time; $A P T T$, activated partial thromboplastin time; CTO, chest tube output; $P R B C$, packed red blood cells; FFP, fresh-frozen plasma; PLT, platelets; $M V$, mechanical ventilation.

*Data do not include 2 patients who had tracheostomies for respiratory failure (mechanical ventilation $\geq 2$ weeks).

groups at each observation time point after 8 hours (group A: $127.5 \pm 71.6 \mathrm{~mL}$ vs group B: $300.3 \pm 226.3 \mathrm{~mL}, P<$ .01 ), 16 hours (group A: $277.5 \pm 119.7 \mathrm{~mL}$ vs group B: $440.2 \pm 390.5 \mathrm{~mL}, P<.01$ ), and 24 hours (group A: 354.5
TABLE 3. Incidence of complications

\begin{tabular}{lccc}
\hline Type of complication & $\begin{array}{c}\text { Tirofiban group } \\
(\mathbf{n}=\mathbf{2 0}) \\
\mathbf{0}^{*}\end{array}$ & $\begin{array}{c}\text { Control group } \\
(\mathbf{n = 6 8 )}\end{array}$ & \\
\hline 20 (29\%)* & Pvalue \\
Atrial fibrillation & 0 & $4(5.8 \%)$ & .61 \\
AMI & 0 & $8(11.7 \%)$ & .24 \\
Bleeding reentry & 0 & $2(2.9 \%)$ & .93 \\
Sternal dehiscence & 0 & $2(2.9 \%)$ & .93 \\
Renal failure & 0 & $2(2.9 \%)$ & .93 \\
PNX & 0 & $2(2.9 \%)$ & .93 \\
MV prolonged (tracheostomy) & 0 & $3(4.4 \%)$ & .79 \\
Stroke & 0 & $2(2.9 \%)$ & .93 \\
Cognitive changes & 0 & $1(1.4 \%)$ & .98 \\
Death & 0 & $3(4.4 \%)$ & .79 \\
\hline AMI & 0 & 0 & -
\end{tabular}

$A M I$, Acute myocardial infarction; $P N X$, pneumothorax; $M V$, mechanical ventilation.

${ }^{*}$ Number of patients with complications. Some of the 20 patients in the control group had more than 1 complication.

$\pm 139.6 \mathrm{~mL}$ vs group B: $544.5 \pm 488.7 \mathrm{~mL}, P<.01$; Figure $3)$. No myocardial infarctions (diagnosed when creatine kinase MB increased by 5 to 10 times the upper normal limit) occurred postoperatively in group A, but 2 were observed in group B. Ejection fractions were also preserved (ejection fraction $=0.554$ in group A vs 0.572 in group B).

Significant differences were found between the 2 groups in mechanical ventilation time and length of stay in the ICU and in the hospital; however, the incidence of complications was higher in group B, in which 20 (29\%) patients had complications (Table 3).

\section{Discussion}

Bleeding complications are a constant problem after cardiac surgery, with $4 \%$ of patients requiring reentry into the operating theater after the first 24 hours after the operation. Nonsurgical bleeding is responsible for $50 \%$ to $60 \%$ of this reopening. ${ }^{10}$ Bleeding complications are related to the use of heparin, the onset of fibrinolysis platelet dysfunction, and a combination of these factors. Platelets are partially activated by heparin and are diluted, destroyed, and modified during CPB because of the adhesion to circuit surfaces, aggregation, and activation. Therefore, after $\mathrm{CPB}$, a deficiency in platelet number and function prolongs bleeding times and contributes to postoperative bleeding.

Platelet-mediated coronary thrombosis is the primary pathophysiologic mechanism of acute coronary syndrome and is the main reason for the requirement for surgical intervention. ${ }^{11}$ The final common pathway of platelet aggregation that leads to thrombotic occlusion of coronary arteries involves the cross-linking of receptor glycoprotein IIb/IIIa 
on adjacent platelets by adhesive plasma proteins, above all fibrinogen. Clinical trials of several glycoprotein IIb/IIIa inhibitors (abciximab, eptifibatide, and tirofiban) have demonstrated an unequivocal clinical benefit of this potent antithrombotic therapy in patients with acute coronary syndrome (irrespective of presence of percutaneous transluminal coronary angioplasty), and in the future, an increasing number of patients are likely to undergo treatment with these molecules. ${ }^{12,13}$

Nevertheless, a significant number of patients may still require urgent or emergency coronary artery bypass grafting after this treatment: the main concern for the immediate treatment of these patients is the potential for increased risk of bleeding caused by the potent antiplatelet effect of these agents. Since their approval for clinical use, more data exist regarding the abciximab molecule (Reopro). Preoperative treatment with abciximab does not increase surgical mortality, but exposure before an operation has been reported to increase postoperative bleeding and transfusion requirements and is associated with a higher incidence of mediastinal reentry. ${ }^{14}$ In our study the infusion of tirofiban hydrochloride immediately before surgical intervention did not adversely affect clinical outcome and did not have any deleterious effect on postoperative bleeding, maintaining hemoglobin and platelet counts at stable levels. Our ongoing study shows that patients may safely undergo an operation without increased incidence of transfusion or reexploration rates when exposed preoperatively to tirofiban.

\section{References}

1. The RESTORE Study Group. Effects of platelet glycoprotein IIb/IIIa blockade with tirofiban on adverse cardiac events in patients with unstable angina or acute myocardial infarction undergoing coronary angioplasty. Circulation. 1997;96:1445-53.

2. Prism-Plus Study Investigators. Inhibition of the platelet glycoprotein $\mathrm{IIb} / \mathrm{III}$ a receptor with tirofiban in unstable angina and non-Q wave myocardial infarction. $N$ Engl J Med. 1998;338:1488-97.

3. Dyke CM, Bhatia D, Lorenz TJ, et al. Immediate coronary artery bypass surgery after platelet inhibition with eptifibatide: results from PURSUIT. Ann Thorac Surg. 2000;70:866-72.

4. Dyke C, Bhatia D. Inhibitors of the platelet receptor glycoprotein $\mathrm{IIb} / \mathrm{III}$ a and complications during percutaneous coronary revascularization. Management strategies for the cardiac surgeon. J Cardiovasc Surg. 1999;40:505-16.

5. Dyke CM. Safety of glycoprotein IIb/ IIIa inhibitors: a heart surgeon's perspective. Am Heart J. 1999;138:S307-16.

6. Hiramatsu Y, Gikakis N, Anderson HL 3rd, Gorman JH 3rd, Marcinkiewicz C, Gould RJ, et al. Tirofiban provides "platelet anesthesia" during cardiopulmonary bypass in baboons. J Thorac Cardiovasc Surg. 1997;113:182-93.

7. Higgins TL, Estafanous FG, Loop FD, Beck GJ, Blum JM, Paranandi L. Stratification of morbidity outcome by preoperative risk factors in coronary artery bypass patients. A clinical severity score. JAMA. 1992;267:2344-8.

8. Buckberg GD. Anterograde/retrograde blood cardioplegia to ensure cardioplegic distribution: operative techniques and objectives. J Card Surg. 1989;4:216-38.

9. Buckberg GD. Strategies and logic of cardioplegic delivery to prevent, avoid and reverse ischemic and reperfusion damage. J Thorac Cardiovasc Surg. 1987;93:127-39.

10. Woodman RC, Harker LA. Bleeding complication associated with cardiopulmonary bypass. Blood. 1990;76:1680-97.

11. Chesebro JH, Fuster V. Thrombosis in unstable angina. $N$ Engl J Med. 1992;327:192-4.

12. Koneti Rao A, Sun L, Hiramatsu Y, Gorman JH 3rd, Edmunds LH. Glycoprotein IIb/IIIa receptor antagonist tirofiban inhibits thrombin generation during cardiopulmonary bypass in baboons. Thromb Haemost. 1999;82:140-4.

13. Bathia D, Dyke C, Cook J, et al. The impact of abciximab (ReoPro) on bleeding after emergency coronary artery bypass grafting [abstract]. 11th Annual Update: Cardiac and General Thoracic Surgery. American College of Chest Physicians, 1999.

14. Lewis W, Collard CD. Does perioperative antithrombotic therapy increase the likelihood of a postoperative coagulopathy after cardiac surgery? Anesthesiology. 2000;92:1499-501. 